\title{
Conceptual Design and Structural Analysis of an Open Rotor Hybrid Wing Body Aircraft
}

\author{
Frank H. Gern ${ }^{1}$ \\ NASA Langley Research Center, Hampton, VA 23681
}

\begin{abstract}
Through a recent NASA contract, Boeing Research and Technology in Huntington Beach, CA developed and optimized a conceptual design of an open rotor hybrid wing body aircraft (HWB). Open rotor engines offer a significant potential for fuel burn savings over turbofan engines, while the HWB configuration potentially allows to offset noise penalties through possible engine shielding. Researchers at NASA Langley converted the Boeing design to a FLOPS model which will be used to develop take-off and landing trajectories for community noise analyses. The FLOPS model was calibrated using Boeing data and shows good agreement with the original Boeing design. To complement Boeing's detailed aerodynamics and propulsion airframe integration work, a newly developed and validated conceptual structural analysis and optimization tool was used for a conceptual loads analysis and structural weights estimate. Structural optimization and weight calculation are based on a Nastran finite element model of the primary HWB structure, featuring centerbody, mid section, outboard wing, and aft body. Results for flight loads, deformations, wing weight, and centerbody weight are presented and compared to Boeing and FLOPS analyses.
\end{abstract}

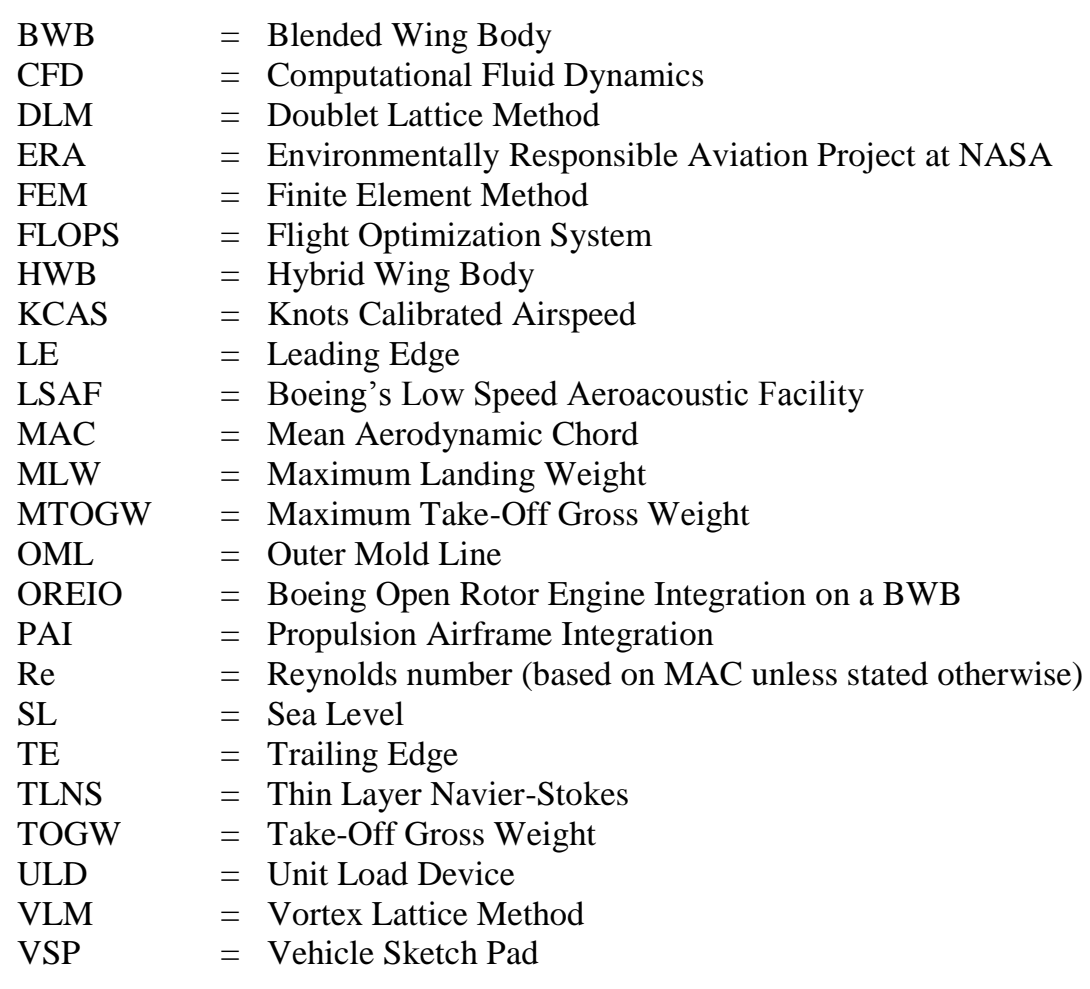

\footnotetext{
${ }^{1}$ Senior Aerospace Engineer, Aeronautics Systems Analysis Branch, Member AIAA.
} 


\section{Introduction}

$\mathrm{H}$

YBRID wing body (HWB) or Blended Wing Body (BWB) aircraft concepts have been considered promising alternatives to conventional tube and wing configurations due to their large potential fuel savings and increased aerodynamic efficiency. ${ }^{1}$ Fuel burn reductions of $25 \%$ and higher have been published for some ultra-high capacity configurations carrying up to 800 passengers. Most notable is the work of Liebeck and his co-workers at The Boeing Company. Their 450 passenger BWB-4501L design recently resulted in the $8.5 \%$ scale X-48B flight demonstrator (Fig. 1). ${ }^{2}$

A significant difficulty in dealing with HWB design optimization has always been the lack of a data base of known "flying" designs which may serve as calibration and validation points for optimization programs like FLOPS, especially when compared to the vast amount of available tube and wing aircraft data. When transitioning from the conceptual to the preliminary design phase, the aircraft designer needs to be sure that the design chosen for further optimization is actually a viable design, and as a result of the lack of validation cases, the development of improved fidelity analysis tools becomes imperative for the conceptual design loop.

To validate the projected fuel burn and noise reduction potential of HWB designs for NASA's Environmentally Responsible Aviation (ERA)

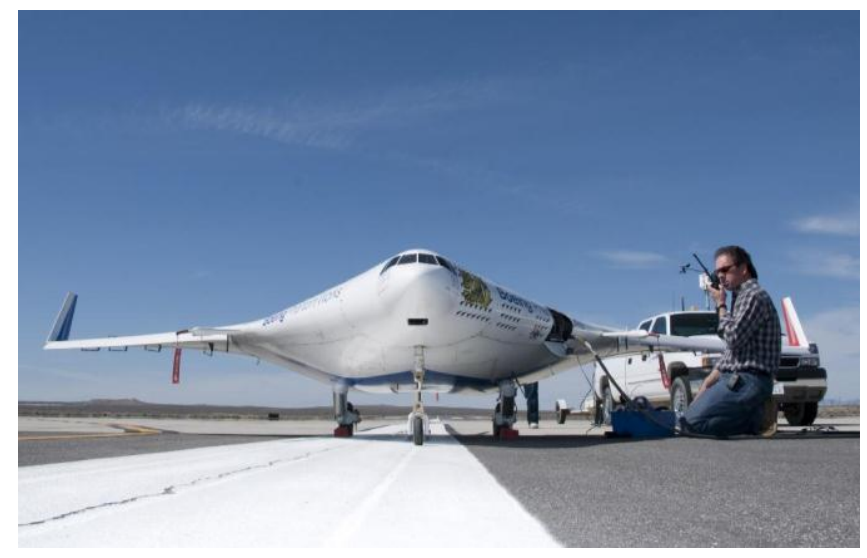

Figure 1: Boeing's X-48B Blended Wing Body flight demonstrator (NASA Photo). project, significant efforts have been put forward to develop advanced structural and aerodynamic analysis tools for HWB conceptual design optimization. Aerodynamic methods improvement has been geared towards increased fidelity in-the-loop methods like enhanced panel codes and computational fluid dynamics (CFD). ${ }^{3}$ Recently developed structures tools include FEM based analyses to provide enhanced capabilities for HWB centerbody sizing and weight estimation. ${ }^{4}$

The HWB concept has been studied with a variety of propulsion options, including podded nacelles, embedded engines, geared fans and open rotors. The open rotor technology has the potential to provide the greatest fuel burn benefits relative to all other potential propulsion options for the HWB. In addition, the HWB offers the potential for noise shielding, thus ameliorating one of the main drawbacks of the open rotor concept. However, open rotor integration with the HWB has not been studied as extensively as podded and embedded engine options. Therefore, the main purpose of a recent Boeing study was to perform a systems analysis of an HWB open rotor concept at the conceptual design level. ${ }^{5}$ This configuration is intended to be utilized by NASA to estimate its overall noise and fuel burn performance.

\section{Boeing Analysis - The Boeing OREIO}

In October 2010, the Aeronautics Systems Analysis Branch at NASA Langley asked Boeing Research and Technology in Huntington Beach, CA to perform a systems analysis of an HWB open rotor concept at the conceptual design level. ${ }^{5}$ Together with test data from a recent acoustics test at Boeing's Low Speed Aeroacoustic Facility (LSAF), ${ }^{6}$ this concept will be used by NASA to estimate the overall noise and fuel burn performance of an open rotor HWB. In accordance with NASA's Environmentally Responsible Aviation (ERA) project goals, the configuration was intended for entry into service by 2025 . The ERA project has a goal of simultaneously reducing noise ( $42 \mathrm{db}$ cumulative below the Stage 4 certification level), fuel burn (50\% reduction compared to currently operating aircraft), and emissions (75\% reduction in nitrogen oxide compared to the current standard). ${ }^{7}$

The study also investigated the problem of propulsion airframe integration (PAI) due to the installation of an open rotor configuration on an HWB. Open rotor engines have unique challenges relative to enclosed turbofans. The rotors are unducted and exposed to flow conditions outside of the engine. The flow field velocities that the rotors are immersed in may be higher than the free stream flow and it may not be uniform, both of these characteristics could increase noise and decrease performance. Absent an enclosure feature, open rotors may also cause changes in the flow conditions imposed on aircraft surfaces along the propulsion system length. At high power conditions such as takeoff and climb out, the stream tube of air that goes through the rotors contracts rapidly causing the boundary layer on the body upper surface to go through an adverse pressure gradient which could lead to flow separation. The 
open rotor HWB configuration must be designed to mitigate these problems in order to reach fuel burn and noise reduction goals. At Boeing, the design was commonly referred to as OREIO, which stands for Open Rotor Engine Integration on an HWB.

\section{A. Performance Requirements}

Performance requirements for the OREIO are based on the NASA ERA requirements stated above, with the primary exception that the cruise Mach number is reduced from 0.85 to 0.80 to better accommodate open rotor propulsion. For the OREIO study, NASA specified an HWB freighter configuration with a 100,000lb payload capacity, including the ULD tare weight. Wingspan is constrained to the $65 \mathrm{~m}(213.25 \mathrm{ft})$ limit for ICAO Code E airports, a reasonable limit for this capacity HWB that, unconstrained, optimizes near this span. Wing folding is not considered in the interest of simplicity, although it may be entertained in future studies if the $65 \mathrm{~m}$ limit proves to be a significant constraint. The objective function for design optimization is fuel consumption. An overview of the OREIO performance requirements is given in Table 1.

Table 1: Boeing OREIO Freighter HWB Performance Requirements. ${ }^{5}$

\begin{tabular}{ll}
\hline \hline Requirement & Value \\
\hline Payload & $100,000 \mathrm{lbs}$ \\
Design range & $6,500 \mathrm{~nm}$ \\
Critical field length (SL Std. Day @ MTOGW) & $10,500 \mathrm{ft}$ \\
Standard for field length & FAR \\
Approach speed & $155 \mathrm{KCAS}$ \\
Landing field length (SL Std Day @ MLW) & $5,200 \mathrm{ft}(\mathrm{dry})$ \\
Initial cruise altitude & $35,000 \mathrm{ft}$ \\
Maximum cruise Mach number & 0.8 \\
Maximum sink rate @ landing & $8 \mathrm{ft} / \mathrm{sec}$ \\
Wingspan constraint & $65 \mathrm{~m}(213.25 \mathrm{ft})$ \\
Measure of merit & Gross payload ton-nm/lb fuel burned \\
\hline \hline
\end{tabular}

\section{B. Boeing OREIO Optimized Design}

The optimization at Boeing was performed using MDOPT, an aerodynamic and multidisciplinary constrained optimization that is based on a design of experiments. The CFD code that was coupled to the optimizer for this work was TLNS (Thin Layer Navier-Stokes). Only the wing and body were modeled for ease of gridding and speed of computation. The optimization constrained the center of pressure between 39\% and 40\% MAC. Thrust effects were accounted for by assuming that thrust equals drag and that the moment arm for the thrust vector was $180 "$ above the center of gravity. The optimization was performed at a lift coefficient of 0.25 and an altitude of $35,000 \mathrm{ft}$. After the MDOPT optimization was complete, the pressure distribution was smoothed using CDISC, a CFD based inverse design tool coupled with CFL3D as a flow solver. The final OREIO geometry was then smoothed manually and is shown in Figure $2 .^{5}$

The vertical tail was checked relative to rules of thumb established by NASA from acoustic testing in the LSAF tunnel. Based on these

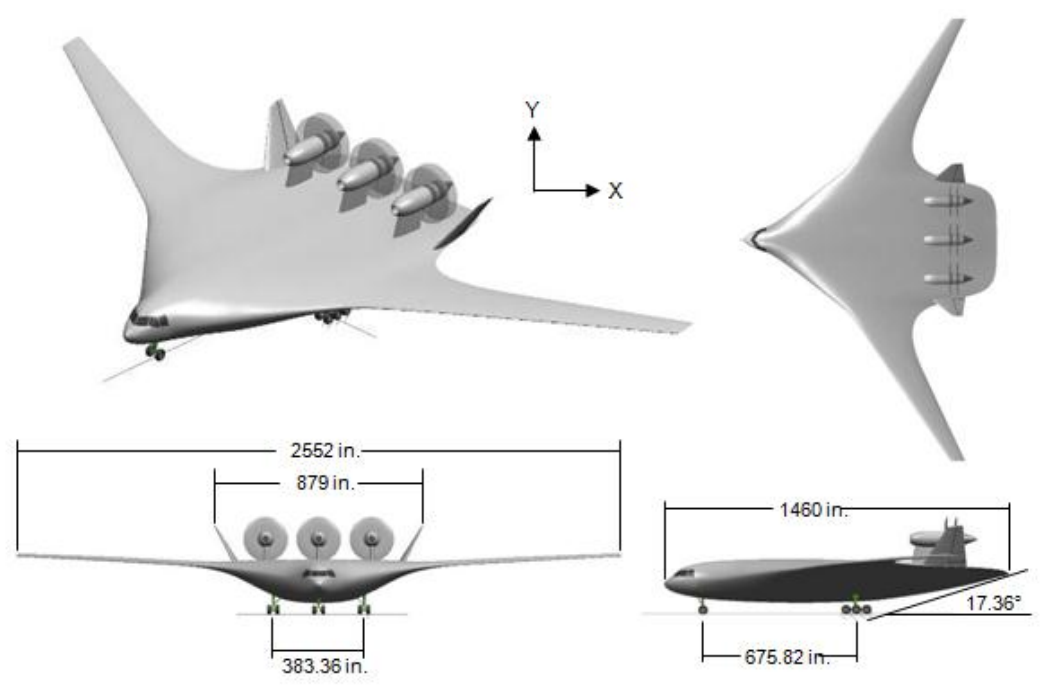

Figure 2: Three-view rendering of Boeing's optimized OREIO HWB. ${ }^{5}$ 
results, NASA suggested sizing rules for the root chord and tip chord relative to the forward rotor diameter. The root chord should be about 1.25 times the front rotor diameter and the tip chord should be about 0.60 times the front rotor diameter. The root chord and tip chord for the revised vertical tail are 1.13 and 0.48 times the front rotor diameter. The revised vertical tail is close to the recommended size for acoustics but slightly undersized. Tail sizing was also checked relative to stability and control requirements. The OREIO configuration and the X-48C are very similar, and the $\mathrm{X}-48 \mathrm{C}$ was evaluated in great detail. Therefore, the $\mathrm{X}-48 \mathrm{C}$ tail volume should be a very good preliminary sizing requirement for the OREIO. The OREIO configuration has approximately the same tail volume as the $\mathrm{X} 48$-C, which implies that the OREIO tails are correctly sized for stability and control. Therefore, the vertical tail size was not increased.

In their NASA contractor report, Boeing published a detailed weight breakdown for the OREIO. This weight breakdown will serve as a baseline for the present studies and is given in Ref. 5 .

Table 2: Boeing OREIO weights statement. ${ }^{5}$

\begin{tabular}{|l|r|}
\hline FUNCTIONAL GROUP & WEIGHT (LB) \\
\hline WING-BODY & 118,387 \\
OUTERWING & 61,143 \\
CENTERBODY & 51,600 \\
AFTERBODY & 5,645 \\
WINGLET NERTICAL TAILS & 2,394 \\
LANDING GEAR & 19,500 \\
ENGINE \& NACELLE & 42,923 \\
ENGINE SYSTEMS & 399 \\
ENGINE PYLON & 6,932 \\
FUEL SYSTEM & 9,209 \\
APU & 1,000 \\
FLIGHT CONTROLS \& HYDRAULICS & 11,798 \\
ELECTRICAL & 3,953 \\
PNEUMATICS \& AIR CONDITIONING & 7,775 \\
ANTIICING & 526 \\
FURNISHINGS AND EQUIPMENT & 5,498 \\
INSTRUMENTS & 1,155 \\
AVIONICS & 3,434 \\
LOAD \& HANDLING & 11,664 \\
\hline WEIGHT EMPTY & 246,548 \\
\hline STANDARD \& OPERATIONAL ITEMS & 2,242 \\
\hline OPERATING WEIGHT & 248,790 \\
\hline MISSION FUEL & 127,010 \\
PAYLOAD & 100,000 \\
\hline MAXIMUM TAKEOFF WEIGHT & 475,800 \\
\hline
\end{tabular}

\section{OREIO FLOPS Model}

The Flight Optimization System (FLOPS) ${ }^{8}$ software is a multidisciplinary system of computer programs for conceptual and preliminary design and evaluation of advanced aircraft concepts. The modular nature of FLOPS allows the user to incorporate new equations and data tables that enable the program to analyze a wide variety of concepts. The current interest in analyzing transports with an HWB configuration has led to the need for a method to rapidly size and analyze conceptual HWB designs. FLOPS is widely used at NASA for evaluating a variety of HWB and other innovative aircraft configurations.

\section{A. FLOPS HWB Centerbody Weights Analysis}

Nickol and McCullers introduced modifications to FLOPS to include an option to layout and size an HWB cabin. ${ }^{9}$ In addition, the FLOPS weight routines were updated with an option to estimate the weight of an HWB. These modifications, combined with propulsion and aerodynamic inputs, enable an HWB mission analysis. The FLOPS user's manual was updated to reflect these changes in the documentation for the weights module. ${ }^{10}$

Nickol and McCullers assume that the cabin is shaped like a "home plate" in baseball, with the point at the nose of the aircraft (see Ref. 9). This home-plate-shaped cabin is sized by assigning an area to each passenger (by using standard packing rules for the number abreast, seat pitch, and passenger class) and allowing for the required number of utility areas (i.e., lavatories, galleys, and closets) based on the number of passengers in each class. The area that is required for passengers and utilities is combined with the areas for aisles and wasted space which results from the specific geometry, to define the required total cabin area. More detailed packing and area assumptions per passenger class can be found in Refs. 9 and 10. 
The HWB centerbody weight prediction routine implemented in FLOPS is based on a regression of centerbody FEM analyses for different passenger size classes. ${ }^{11}$ The same generic HWB centerbody geometry was used to create a family of five transports, sized for approximately 250 to 450 -passengers, at 50-passenger increments. Data obtained from the finite element analysis was used to find the coefficients of a weight estimate equation in the form

$$
W_{\text {cabin }}=K_{s} * 0.316(\text { TOGW })^{0.167}\left(S_{\text {cabin }}\right)^{1.061} \text {. }
$$

The centerbody dimensions can be entered in an input file to analyze an HWB of known geometry, or the dimensions can be calculated based on the number of passengers. Since the derived regression curve is based on five distinct, though very representative centerbody structural layouts, its sensitivity to changes in centerbody geometry is unknown. Therefore, this method is best suited for analyses within a given class and mission profile of a specific platform.

\section{B. FLOPS Aerodynamic Performance Prediction}

Boeing performed a detailed aerodynamic performance optimization on the OREIO vehicle, and for this reason, it was decided to replace the FLOPS based low speed and cruise drag polars by the ones published by Boeing in Ref. 5. Viscous cruise drag predictions for the OREIO by Boeing were compared to other available data and showed excellent agreement with scaled wind tunnel test data from the X-48B flight demonstrator. The procedure for the scaling analysis is based on the Hoerner equations and is described in detail in Ref. 3. A series of drag polars was developed using the same analysis and by scaling Boeing data with respect to altitude and Mach number.

Since the OREIO already went through a detailed sizing and optimization cycle, the FLOPS model was run in analysis mode to obtain a directly comparable weight breakdown based on the actual Boeing OREIO geometry and performance characteristics. The detailed FLOPS weight statement is shown in Table 3. A comparison of Table 2 and Table 3 shows that the FLOPS and Boeing estimates for gross weight and empty weight are within 1\% and 2\% of each other. However, some of the sub component outputs are grouped differently, making detailed comparisons between the two analyses inherently difficult.

Table 3: OREIO Weights statement from FLOPS analysis.

\begin{tabular}{|l|c|}
\hline FUNCTIONAL GROUP & WEIGHT (lbs) \\
\hline WING (incl. outboard wing, mid and aft section) & 63,791 \\
VERTICAL TAIL & 2,381 \\
FUSELAGE (centerbody) & 77,412 \\
LANDING GEAR & 19,404 \\
PAINT & 1,614 \\
$\quad$ STRUCTURE TOTAL & $\mathbf{1 6 4 , 6 0 2}$ \\
ENGINES & 50,254 \\
FUEL SYSTEM-TANKS AND PLUMBING & 3,968 \\
PROPULSION TOTAL & $\mathbf{5 4 , 2 2 2}$ \\
SURFACE CONTROLS & 9,821 \\
AUXILIARY POWER & 661 \\
INSTRUMENTS & 976 \\
HYDRAULICS & 3,894 \\
ELECTRICAL & 2,523 \\
AVIONICS & 2,237 \\
FURNISHINGS AND EQUIPMENT & 254 \\
AIR CONDITIONING & 2,361 \\
ANTI-ICING & 381 \\
\hline SYSTEMS AND EQUIPMENT TOTAL & $\mathbf{2 3 , 1 0 8}$ \\
\hline WEIGHT EMPTY & $\mathbf{2 4 1 , 9 3 1}$ \\
\hline CREW AND BAGGAGE-FLIGHT, 2 & $\mathbf{4 5 0}$ \\
UNUSABLE FUEL & $\mathbf{2 3 3 5}$ \\
ENGINE OIL & $\mathbf{2 4 3 , 9 4 8}$ \\
\hline OPERATING WEIGHT & 100,000 \\
\hline CARGO & $\mathbf{3 4 3 , 9 4 8}$ \\
\hline ZERO FUEL WEIGHT & 128,045 \\
\hline MISSION FUEL & $\mathbf{4 7 1 , 9 9 3}$ \\
\hline RAMP (GROSS) WEIGHT & \\
\hline
\end{tabular}

American Institute of Aeronautics and Astronautics 


\section{OREIO Conceptual Design Structural Finite Element Model}

Boeing performed a detailed aerodynamic performance optimization and analyzed a wide variety of propulsion airframe integration issues associated with open rotor installation on an HWB concept. Unfortunately, it was out of the scope of this effort to perform a comparable structural analysis. Boeing's weight estimates are based on their own conceptual sizing code similar to FLOPS. For this reason, a more detailed structural analysis on the OREIO primary structure was performed to assess the structural weights outputs from the Boeing and FLOPS analyses. This structural analysis is based on a NASTRAN finite element model of the HWB centerbody, mid section, outboard wing, and aft body. ${ }^{4}$

\section{A. VSP Outer Mold Line Data and Centerbody Parameterization}

As an initial step for creating the finite element model of the HWB primary structure, a VSP ${ }^{12}$ model of the OREIO was generated (Figure 3). Geometry data for the structural analysis is based on VSP outer mold line (OML) data and is exported from VSP as triangularized surface data in the format of CTRIA6 finite elements.

To ensure compatibility of the present structural analysis with previous structural modules implemented in FLOPS, the "home plate" geometry introduced by Nickol and McCullers has been used to define the basic parameters of the centerbody finite element model (see Refs. 9 and 10). The centerbody "home plate" geometry is projected onto the HWB OML data and the centerbody geometry is then created by slicing the OML surface data at the home plate boundaries. Details regarding this procedure can be found in Ref. 4.

The complete OREIO primary structure is represented by four components: centerbody, mid section, outboard wing, and aft body. The mid

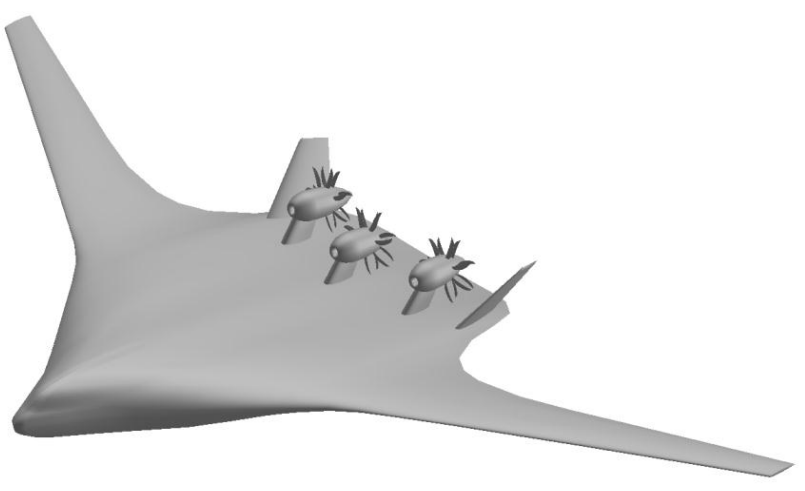

Figure 3: OREIO VSP model. section, outboard wing, and aft body of the HWB are added to the structural model to allow for proper application of wing lift and moment distributions on the centerbody. The chordwise locations of front and rear spars for both mid section and outboard wing are assumed to be at $12.5 \%$ and $62.5 \%$, respectively. However, due to the parametric nature of the structural representation, these parameters can easily be modified to explore other design options. The front bulk head of the centerbody is defined by standard cockpit size assumptions. The aft body section is considered non-pressurized and generally carries the engine loads as well as vertical tails, if present. To highlight the resulting HWB structural representation, Figure 4 shows the OREIO primary structure overlaid to the OML obtained from the VSP model as well as the resulting structural components for FEM modeling.

All structural components are modeled as CQUAD4 finite elements in Nastran. The complete design model for the finite element analysis and optimization features front spars, rear spars, skin sections, side walls, and internal walls if applicable.

a) OML and primary structure overlay

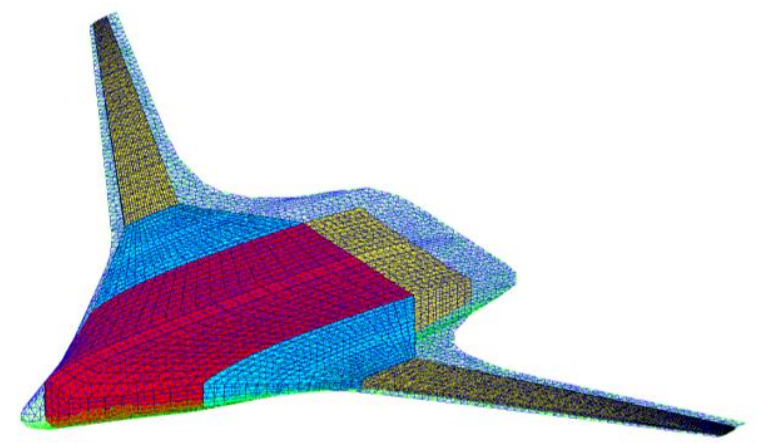

b) Primary structure for FEM modeling

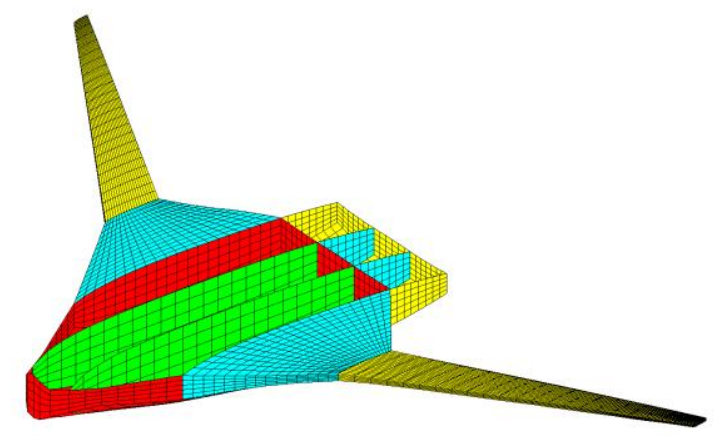

Figure 4: OREIO OML mapping and primary structure overlay for FEM modeling.

6

American Institute of Aeronautics and Astronautics 


\section{B. Centerbody Structural Design Options}

Three different centerbody design options are available for structural analysis and optimization, a single bay, a three-bay, or a five-bay design. The model utilizing the basic single bay centerbody design does not feature any internal walls and will be shown to highly overpredict centerbody weights in section VI. The three- and five-bay centerbody designs are representative of actual centerbody structures from preliminary design studies similar to the one presented in Ref. 13. The internal walls provide significant displacement relief and allow for an accurate application of displacement constraints in the design model.

\section{Stiffened Panel Modeling}

Researchers at The Boeing Company in Huntington Beach, California have been developing highly-integrated stitched-composite airframe structures tailored and optimized to exploit the orthotropic nature and processing advantages of carbon fiber materials. The Pultruded Rod Stitched Efficient Unitized Structure (PRSEUS) concept departs from conventional laminated composite design practices, manufacturing processes, and tooling techniques. This leads to substantial reductions in manufacturing and assembly costs while yielding the higher levels of structural performance that are critical for HWB airframes. ${ }^{13-15}$ The PRSEUS approach is deemed necessary for the HWB because of its potential to enable the flat-sided pressure cabin to be weight-competitive with traditional circular fuselage shells.

Modeling stiffened panels, and even more so the PRSEUS structural concept, in a conceptual design environment presents significant challenges in terms of FEM model size and complexity. However, in order to realistically apply displacement constraints for design optimization, the overall stiffness of the structural components must be matched. For this purpose, the 12I/T**3 entry in the Nastran PSHELL card has been modified from its default value of 1 to a value reflecting the actual bending moment of inertia of the PRSEUS panels vs. the bending stiffness of a homogenous shell. ${ }^{16}$

\section{Nastran Design Optimization Model}

For structural analysis and optimization of the OREIO, a fully aeroelastic finite element model has been developed in MSC Nastran. Details of the baseline structural and aerodynamic modeling can found in Ref. 4. To properly account for inertia effects and maneuver loads, systems weights, payload, and fuel weight distributions have been added to the structural model. Concentrated masses represent landing gears and open rotor engines, and are also distributed along the elastic axis of the vertical tail. Proper application of all nonstructural weights to the aeroelastic model will allow for using Nastran's TRIM solution to individually trim the airplane for each maneuver load case during the optimization, leading to more realistic results and structural weight predictions (Figure 5).

To apply aerodynamic loads, the original VSP OML was sliced at given spanwise locations to obtain planform geometries for the Nastran CAERO doublet lattice panels. Wing twist and camber distributions are extracted from VSP airfoil data and applied to the aerodynamic panels as a fixed downwash. Aerodynamic loads are splined onto the front and rear spars to accurately apply forces and moments to the structure. Details regarding the aeroelastic modeling can be found in Ref. 4.

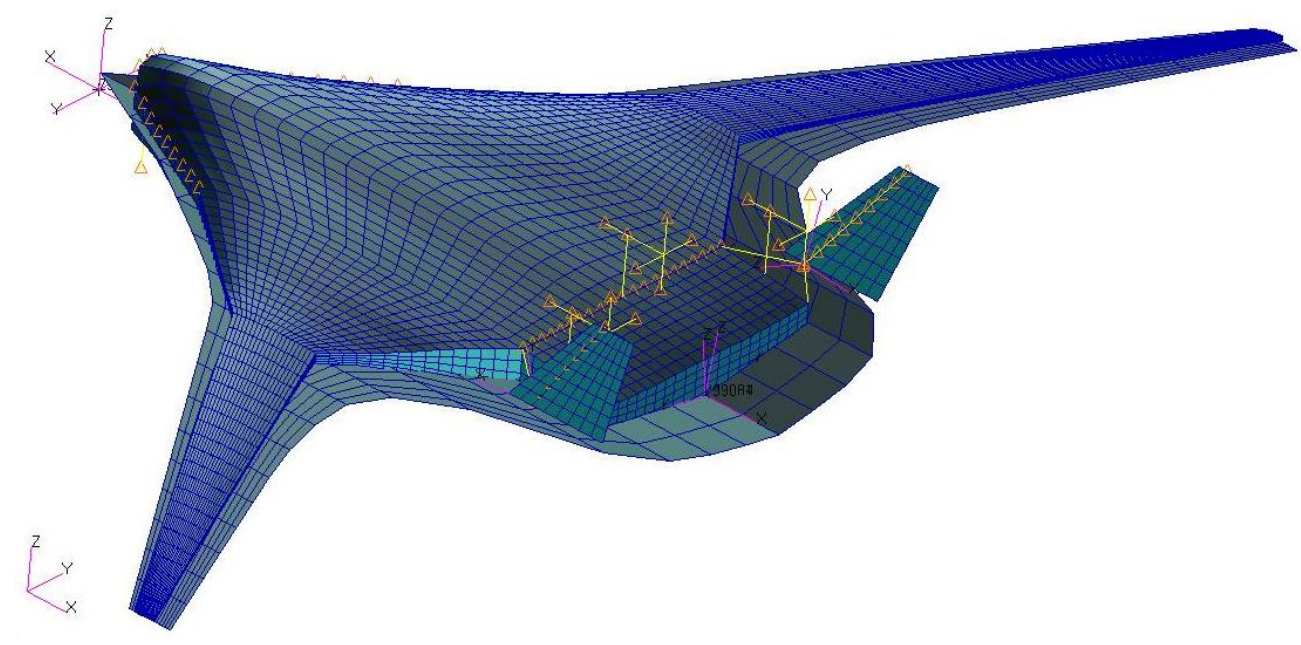

Figure 5: Nastran design model of the OREIO centerbody, aft body, and wing structure. 
Nastran's Solution 200 (SOL200) was used for structural analysis and design optimization. ${ }^{17}$ In SOL200, the design optimization is multi-disciplinary in the sense that the optimization for all load cases is performed simultaneously. The total structural weight was used as an objective function to be minimized.

Design variables include the individual panel thicknesses of the centerbody, mid section, outboard wing, and aft section elements. Thickness constraints are placed on the design variables to account for minimum gauge limitations. Stress constraints are based on PRSEUS material properties. Displacement constraints for the centerbody under the 1.33P pressure condition (see section E) are based on maximum allowable deformations to maintain aerodynamic flow quality. As outlined in Ref. 4, the model is fully scalable and allows for arbitrary numbers of elements in the $\mathrm{x}, \mathrm{y}$, and z-directions. However, typical design models for the present analyses have been found to work well with 2,500 to 3,500 CQUAD4 elements, resulting in 15,000 to 20,000 degrees of freedom.

\section{E. Load Cases for Structural Sizing}

Loads assumptions for commercial transport aircraft are defined in FAR-25 (Federal Aviation Regulations Part 25 - Airworthiness Standards: Transport Category Aircraft). To fully satisfy these regulations, the airframe manufacturer generally has to analyze thousands of different load cases throughout the flight envelope to identify the critical ones. Only a subset of critical load cases is used in preliminary design, with an even smaller subset of only a few load cases being used for conceptual design optimization. A comprehensive overview and load case development of design critical load cases for HWB platforms is presented in Ref. 18.

Different combinations of payload and fuel weight scenarios have been evaluated to develop worst case assumptions for each load case. As a result, the load cases used for structural sizing of the OREIO are

- $\quad 2.5$-g limit load (full payload, zero fuel)

- 2.5-g limit load (full payload, full fuel)

- $\quad$-1.0-g limit load (full payload, zero fuel)

- $\quad$-1.0-g limit load (full payload, full fuel)

- 2.0-g taxi bump (full payload, full fuel)

- $1.33 \mathrm{P}$ cabin overpressurization (centerbody only)

A safety factor of 1.5 has been applied to the limit load stress margins to account for ultimate loads. Only symmetric load conditions are currently implemented, therefore only a half-model is required for analysis and design optimization. As Figure 5 shows, a full model can easily be created from the half model by mirroring the aeroelastic model across the x-z-plane. This will allow for the implementation of asymmetric load cases like engine out conditions or dynamic overswings. Some of these cases are driven by asymmetric thrust conditions and high side loads on the vertical tails. As a result, adding these load cases would likely increase the fidelity of aft body sizing and optimization.

\section{F. Structural Optimization and Weight Calculation}

The structural weight is automatically calculated by Nastran when using weight as an objective function. To obtain the total centerbody weight, the PRSEUS material density of $0.057 \mathrm{lb} / \mathrm{in}^{3}$ is multiplied by a correction factor accounting for weight penalties due to production breaks, the centerbody leading edge, main and cargo deck floors, doors and supports, maintenance platforms, lightning protection, as well as paint, primer, and sealant. A front bulkhead simulates a closed pressure vessel for the 1.33P internal pressure load without the need to model the complex cockpit geometry, while still applying realistic loads to the centerbody front section.

The combined weight of cockpit and nose is assumed to be constant at 1,995lbs. Generally, this number does not vary significantly with aircraft size due to commonality requirements of modern aircraft family designs. Similar non-optimum factors were applied to the wing weight calculation. For comparison purposes, non-structural wing weight factors are identical to the ones used in FLOPS. More details regarding the different wing weight terms in FLOPS and the wing weight calculation are discussed in section VI.

\section{Nastran Structural Optimization}

\section{A. Analysis Details for Different Load Cases}

A detailed centerbody weights analysis and code validation for the presented FEM tool is given in Ref. 4. There, a centerbody weights prediction tool developed by The Boeing Company was used to validate the centerbody weight calculations from the finite element model. A BWB450 type centerbody design was chosen to generate a suitable centerbody geometry using the home plate approach described previously. 
For the present OREIO analysis, structural optimization for the centerbody as well as the mid section, outboard wing, and aft body was enabled. The results shown are for a three-bay centerbody design, which is the most realistic structural configuration for this aircraft size. In section VI, it will be shown that the centerbody weight for a single bay design would be unrealistic, while a five bay design will prove impractical due to bay size constraints to accommodate the ULD containers. Figure 6 shows deformation results for the initial and optimized OREIO configuration for both the $1.33 \mathrm{P}$ internal pressure load and the $2.5 \mathrm{-g}$ maneuver load case.

a) Initial configuration (1.33P)

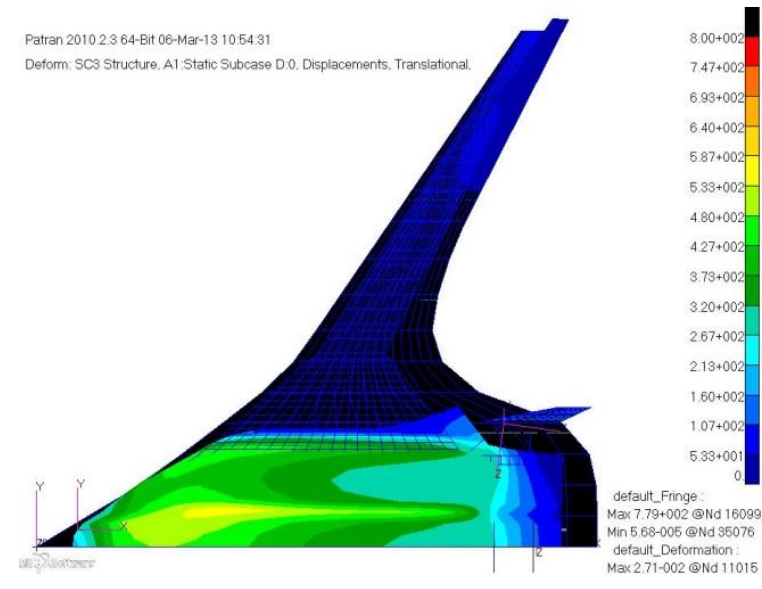

b) Optimized configuration (1.33P)

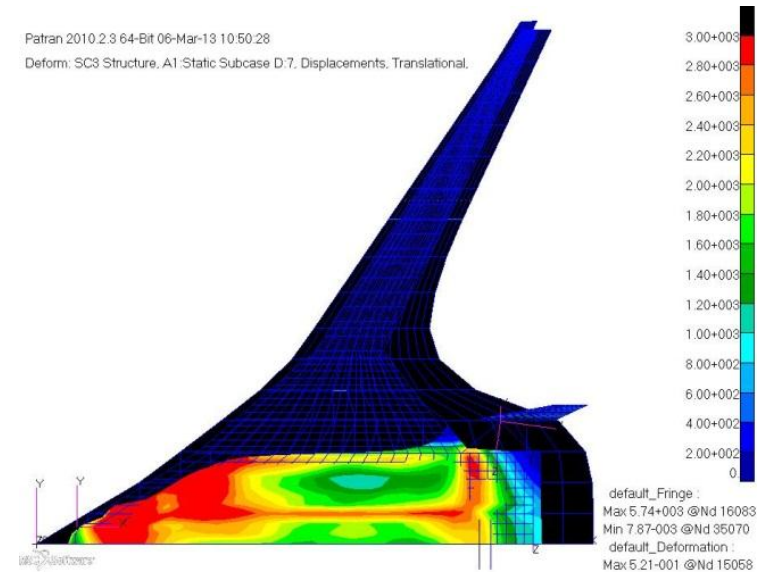

c) Initial configuration $(2.5-\mathrm{g})$

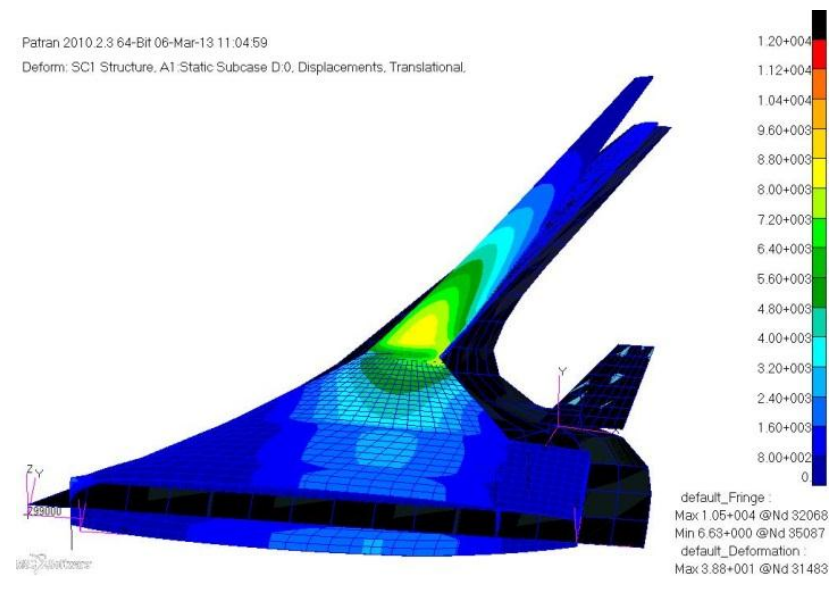

d) Optimized configuration (2.5-g)

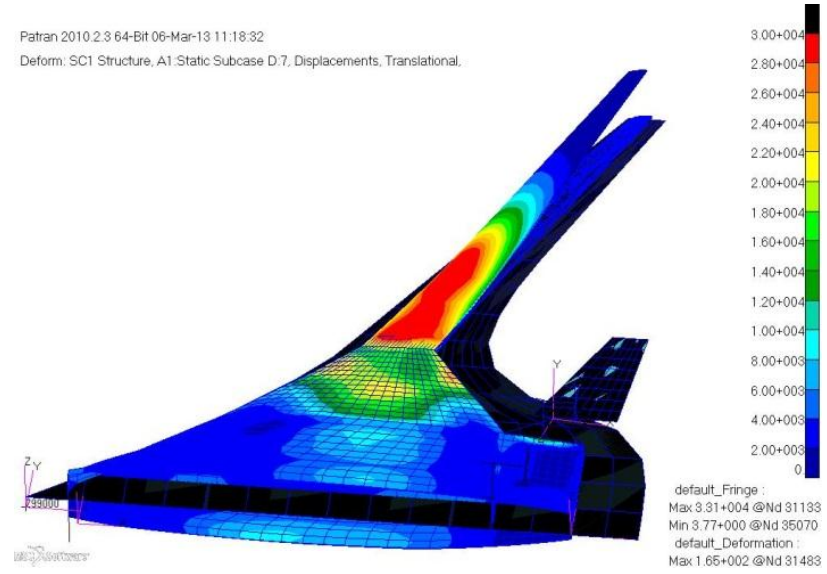

Figure 6: OREIO Initial and optimized structural deformations and stress tensors for 1.33P cabin overpressurization and 2.5-g maneuver load (deformations not to scale).

\section{B. Convergence History}

Convergence for the OREIO design optimization model was fast. In Ref. 4, model scalability was checked by using different numbers of CQUAD4 elements on the $\mathrm{x}, \mathrm{y}$, and z-directions, resulting in centerbody FEM models of 256, 480, 750, and 1000 elements. It was shown that weight convergence is almost independent of model size, indicating excellent scalability of the model.

To investigate the influence of the individual load cases on the overall centerbody weight, individual optimizations were performed for each of the load cases. A comparison of convergence histories for the individual analyses with the results from a simultaneous optimization of all load cases shows that the centerbody is almost 
entirely sized by the $1.33 \mathrm{P}$ internal pressure condition, as the weight obtained from the pressure load case is almost identical to the weight obtained from a simultaneous optimization (Figure 7).

Centerbody weights obtained from the maneuver load cases result in much lower numbers, with the majority of the element thicknesses running down to the minimum gauges. For the 2.5-g and $-1.0-\mathrm{g}$ maneuver load cases, hard convergence is achieved after only a few cycles. Closer examination of the results shows that only a small region of the rear spar is sized by the $2.5-\mathrm{g}$ maneuver load.

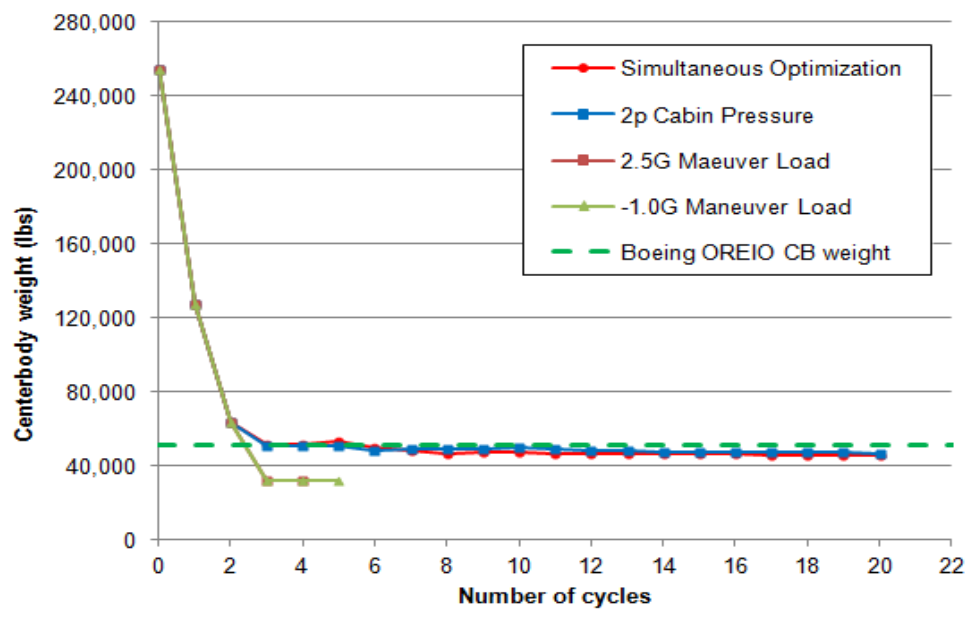

Figure 7: OREIO Centerbody weight convergence history for individual load cases vs. simultaneous optimization of all load cases.

\section{Structural Sizing and Weights Results}

\section{A. Centerbody Design Options and Weight Comparisons}

As already mentioned, centerbody designs featuring internal walls are more representative of layouts utilized for detailed preliminary design studies. The internal walls provide significant displacement relief for the centerbody walls under the internal pressure load. Therefore, representative stress and strain distributions in the structure lead to more realistic optimization results. This is of particular importance for scaling studies, where centerbody designs for different aircraft size classes are studied.

a) Single-bay design

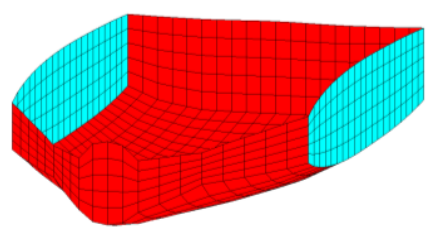

b) Three-bay design

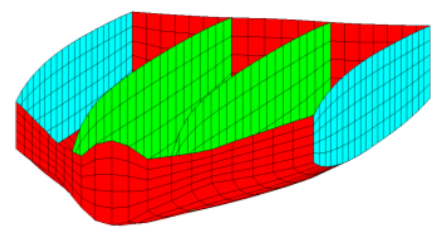

c) Five-bay design

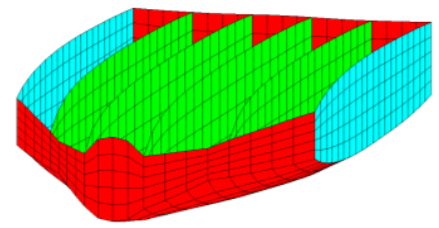

Figure 8: OREIO Centerbody design options for structural analysis and optimization.

Three different design options were investigated: a single-bay design, a three-bay design and a five-bay design (Figure 8). Two- or four-bay designs were not considered for this study, since an internal wall in the centerline of the vehicle was deemed to lead to challenging structural issues in the front section of the centerbody where the cockpit connects to the front bulkhead. Figure 9 shows stress tensor results for all three design options for the $2 \mathrm{P}$ over-pressurization, which is the main sizing load case for the centerbody.

a) Single-bay design

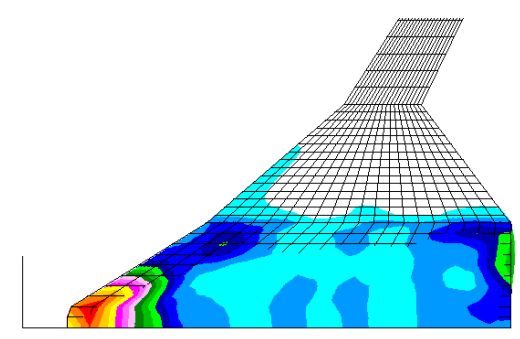

b) Three-bay design

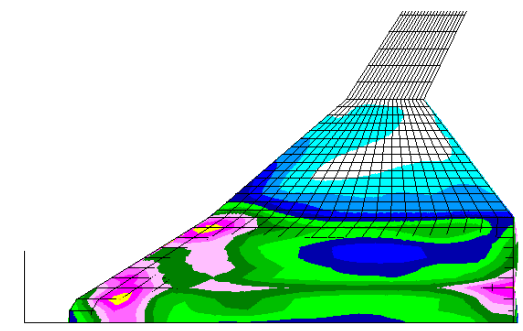

c) Five-bay design

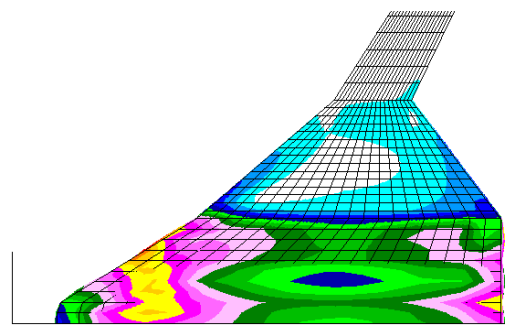

Figure 9: OREIO Centerbody deformation and stress tensor results for all three design options. 
For identical displacement constraints on the centerbody nodes, the three- and five-bay designs lead to lighter weight configurations, while the single-bay design proves to be an unrealistic option due to the large centerbody weight penalty. The threebay layout was chosen as the most practical design option for the OREIO. The five-bay design, while still providing additional weight benefits over the three-bay design, would not leave enough clearance for ULD containers.

Figure 10 shows optimization results for all three centerbody design options. Note that the cockpit weight was assumed to be identical for all three options, as the cockpit size would not vary significantly with the number of

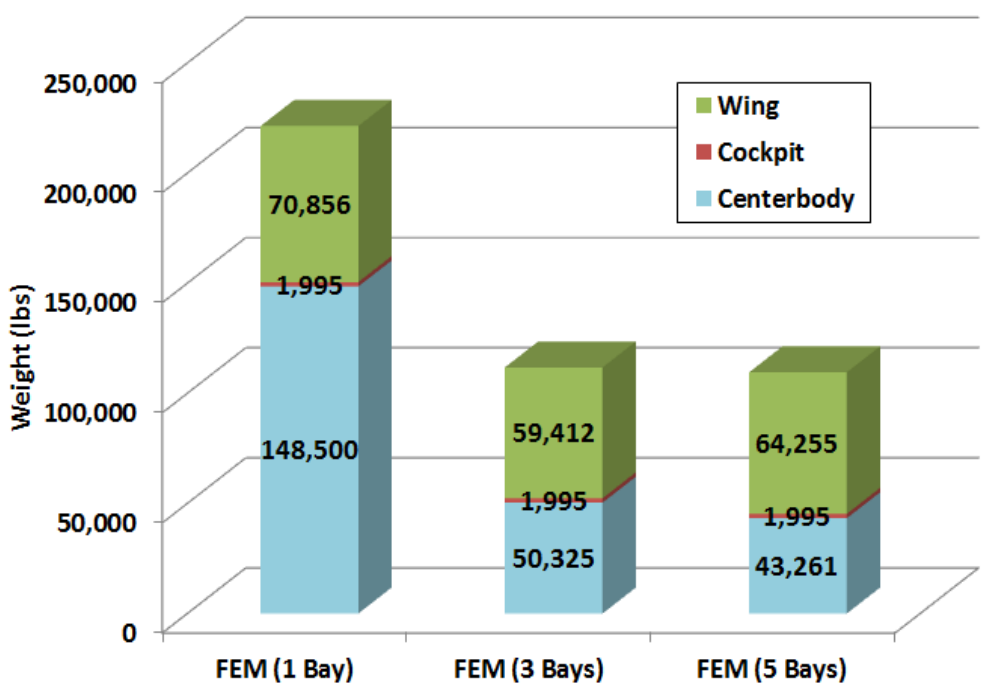

Figure 10: Comparison of structural weights for different centerhodv lavouts centerbody bays. Figure 10 also shows that differences in the centerbody design result in some wing weight variation. Although this may be counterintuitive at first sight, this behavior is a result of the optimizer trying to minimize the total weight of the structure. In some cases, a structural penalty in the wing weight may still lead to an overall structural weight reduction due to the fact that forces and moments on the centerbody are being reduced. Overall, the wing weight variation is relatively small since the wing is mainly sized by the $2.5-\mathrm{g}$ maneuver load condition.

\section{B. Comparison of Structural Weights from Different Analysis Models}

Figure 11 shows a comparison of the structural weight breakdowns from all three analyses for the three-bay centerbody design: FEM-based, Boeing, and FLOPS. Purposely, no effort was made to calibrate or match numbers to one specific analysis. Note that the number of significant digits in the results is not an indicator of the accuracy or high fidelity of the analyses. However, for validation and traceability purposes, the direct analyses results are shown without truncation or rounding. All three analyses are based on different sets of assumptions and on different levels of fidelity. Nonetheless, the weights results from the different models are in good agreement with each other.

Centerbody Weight: For the FEM-based analysis, the cockpit weight is bookkept separately and therefore shown as an individual item. The combined weight of cockpit and centerbody from the FEM analysis $(52,320 \mathrm{lbs})$ is within $2 \%$ of the Boeing value $(51,600 \mathrm{lbs})$. Note that this agreement is not due to correction factors used to tune weights outputs but is a direct result from the analysis. The calibration and validation procedure for the FEM model is described in detail in Ref. 4. FLOPS predicts a significantly higher centerbody weight than both the FEM and Boeing analyses (77,412lbs).

Wing Weight: While FLOPS predicts the lowest wing weight $(49,419 \mathrm{lbs})$, the deviation between the Boeing wing weight $(61,143 \mathrm{lbs})$ and the FEM-based wing weight $(59,412 \mathrm{lbs})$ is less than 3\%. For both FLOPS and FEM, the nonstructural weights terms for the wing weight are calculated using the same assumptions. ${ }^{9}$ The FLOPS methodology includes three weights

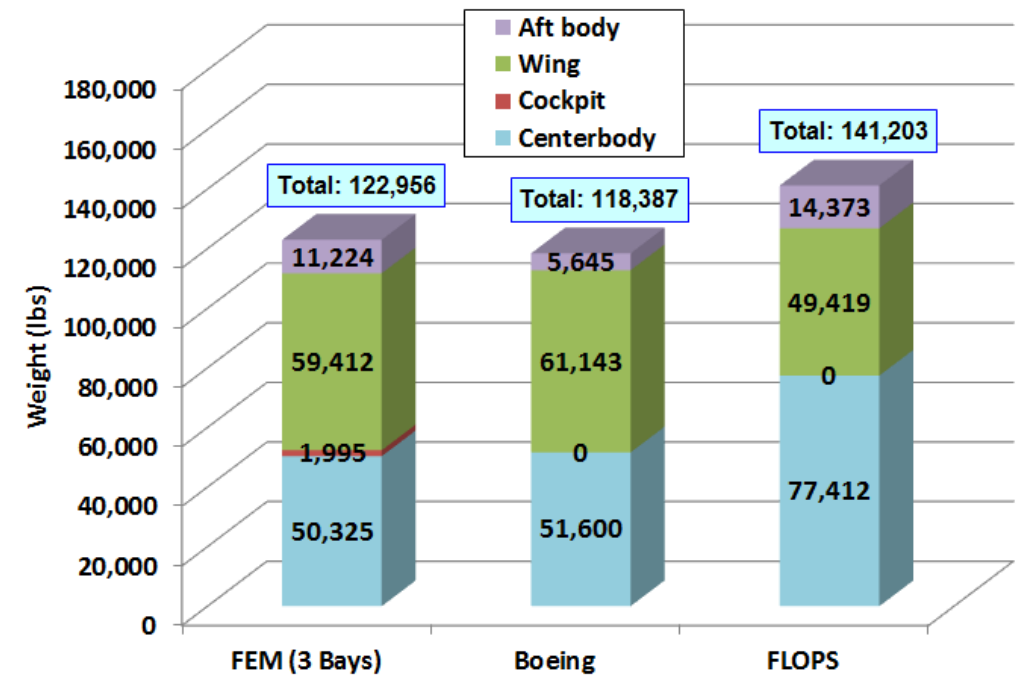

Figure 11: OREIO Weights comparison for different analyses. 
terms which were combined to calculate the total wing weight:

- Term 1 is calculated from the wing bending loads,

- Term 2 represents control surfaces and shear material,

- Term 3 depends entirely on the wing area and covers miscellaneous wing items.

Since the FEM analysis directly replaces Term 1, a multiplication factor is derived from the FLOPS analysis to calculate the total wing weight based on the ratios of Terms 1,2, and 3.

Another option would be to only use Term 1 from the FEM analysis and calculate the total wing weight by keeping Terms 2 and 3 from the FLOPS analysis. This would result in a significantly lower total wing weight for the FEM-based analysis $(52,936 \mathrm{lbs})$ and indicates that FLOPS tends to underestimate the structural wing weight portion for this design. Applying this procedure would also reduce the versatility of the FEM model, as the obtained weight number would only be valid for the exact same geometry; an additional FLOPS analysis would always be required to calculate the additional wing weight terms.

Aft Body Weight: For HWB analyses in FLOPS, a Term 4 is added to the wing weight breakdown to account for the weight of the aft body. The FEM based aft body weight prediction of $11,224 \mathrm{lbs}$ is about $22 \%$ lighter than the FLOPS aft body weight $(14,373 \mathrm{lbs})$, while the Boeing analysis only predicts 5,645lbs. These numbers show that the highest uncertainty for structural weight prediction lies in the determination of the weight of the aft body structure. The aft body weight is primarily driven by inertia and thrust loads of the engines, side loads on the vertical tails during engine out conditions, and control surface hinge moments of the large centerline trailing edge flaps. Adding more load cases like asymmetric thrust conditions and high side loads on the vertical tails are expected to reduce the uncertainty associated with aft body weight results.

Total Structural Weight: Figure 11 shows that the FLOPS analysis predicts a higher centerbody weight, while underpredicting the wing weight as compared to the two other models. Due to this compensation effect, the total structural weight from the FLOPS analysis $(141,373 \mathrm{lbs})$ still comes reasonably close to both the Boeing prediction $(118,387 \mathrm{lbs})$ and the FEM model (122,956lbs). The FEM model and Boeing analysis are within $4 \%$ of each other for the total structural weight.

\section{General HWB Scaling Trends}

The FEM based weights tool was previously used to calculate centerbody structural weights for a scaling study by Nickol using a family of HWB designs ranging from regional jet size (98 passengers) to very large twin-aisle jet size (400 passengers). ${ }^{4,19}$ The principal motivation for this scaling study was due to the fact that initial HWB concepts focused on very large applications with capacities for up to 800 passengers. More recent studies have focused on large, twin-aisle class HWBs with passenger capacities in the 300-450 range. Efficiently scaling the HWB concept down to single aisle or smaller sizes is challenging due to geometric constraints, potentially reducing the desirability of this concept for applications in the 100-200 passenger capacity range or less. In order to quantify this scaling challenge, five advanced conventional (tube-and-wing layout) concepts were compared to equivalent HWB concepts in terms of fuel burn performance. ${ }^{19}$

In Ref. 4, a passenger size of about 260 to 300pax was found to represent the centerbody size where switching from a three-bay to a five-bay layout would be reasonable. The five-bay design, while still providing additional weight benefits over the three-bay design, would not leave enough clearance to accommodate ULD containers or provide for reasonable seating arrangements in the extremely narrow bays for smaller HWB concepts. The analyzed OREIO freighter HWB would

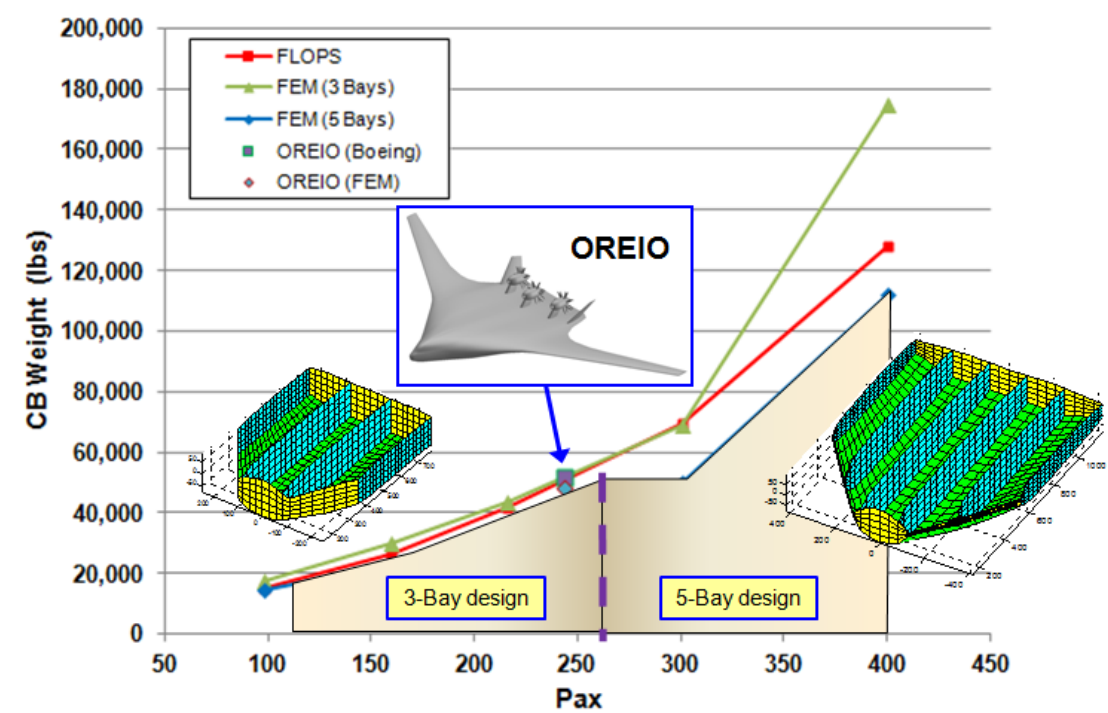

Figure 12: HWB Centerbody design space for three vs. five bay designs.

American Institute of Aeronautics and Astronautics 
be equivalent to a 244 passenger aircraft. Figure 12 shows that the OREIO centerbody weights for both the Boeing and FEM analyses agree extremely well with the trends developed in Ref. 4.

\section{Conclusions}

This paper presents a fast and flexible finite element model for structural analysis, optimization, and weight calculation for HWB designs. The method is highly scalable and can be used to analyze any HWB structure based on a VSP model of the air vehicle and a set of predefined structural parameters. Since the model is based on a direct structural analysis rather than regression or approximation methods, the weight results are suitable for scaling studies or higher-risk alternative configurations. The high degree of scalability allows for flexible numbers of elements in the chordwise, spanwise, and thickness directions, resulting in variable model sizes, degrees of freedom, design variables, and design constraints, rendering this model highly suitable for exploring design sensitivities and convergence studies.

The model has been validated using available data from preliminary design efforts by The Boeing Company, FLOPS centerbody weight results, aerodynamic data from X-48B wind tunnel testing, and Vorview vortex lattice analyses. The structural optimization has been expanded to calculate the centerbody, mid section, outboard wing, and aft body weights. Results from the FEM optimization for the OREIO open rotor HWB agree well with results from Boeing and FLOPS analyses. It was shown that the centerbody structural design affects not only the centerbody weight, but also impacts wing weights, as the optimizer may slightly increase wing weights to reduce the total weight of the HWB primary structure. For the size and design class of the OREIO concept, a three-bay centerbody design was shown to be the most viable option. A single bay design would result in significant centerbody weight penalties, while a five-bay design proves impractical due to constraints from ULD container sizes and reasonable passenger seating arrangements.

The present study confirms earlier claims that the advantages of a five-bay design become more significant for passenger cabin sizes upwards of about 270 passengers, while a three-bay centerbody is more practical for smaller HWB vehicles. However, the exact transition point from a three to a five-bay design depends on the specific centerbody design parameters. Therefore, it is recommended to perform the structural and weights analysis for both options and base the final layout decision on the obtained results.

For more in-depth analyses, the design model can easily be expanded to cover a larger variety of loads and analysis options, including gust loads, trim analyses, stability and control options, or flutter constraints.

\section{Acknowledgements}

The author would like to thank his co-workers Craig L. Nickol and Andrew S. Hahn at NASA Langley for their contributions and valuable discussions. The work was supported by Dr. Fay Collier under the NASA Environmentally Responsible Aviation (ERA) project.

\section{References}

1 Liebeck, R.H., "Design of the BWB Subsonic Transport", AIAA-2002-0002, 40 ${ }^{\text {th }}$ AIAA Aerospace Sciences Meeting and Exhibit, January 14-17, 2002, Reno, NV.

2 Risch, T., Cosentino, G., Regan, C.D., Kisska, M., and Princen, N., "X-48B Flight-Test Progress Overview,” AIAA-20090934, $47^{\text {th }}$ AIAA Aerospace Sciences Meeting and Exhibit, January 5-8, 2009, Orlando, Florida.

3 Gern, F.H., "Improved Aerodynamic Analysis for Hybrid Wing Body Conceptual Design Optimization," AIAA-2012-0249, $50^{\text {th }}$ AIAA Aerospace Sciences Meeting and Exhibit, January 9-12, 2012, Nashville, Tennessee.

4 Gern, F.H., "Finite Element Based HWB Centerbody Structural Optimization and Weight Prediction," AIAA-2012-1606, $53^{\text {rd }}$ AIAA/ASME/ASCE/AHS/ASC Structures, Structural Dynamics and Materials Conference, April 23-26, 2012, Honolulu, Hawaii.

5 Pitera, D.M., DeHaan, M., Brown, D., Kawai, R.T., Hollowell, S., Camacho, P., Bruns, D., and Rawden, B.K., Blended Wing Body Concept Development with Open Rotor Engine Integration, NASA/CR-2011-217303, The Boeing Company, Huntington Beach, California, November 2011.

6 Czech, M.J. and Thomas, R.H., "Experimental Studies of Open Rotor Installation Effects," AIAA-2011-4047, $3^{\text {rd }}$ AIAA Atmospheric Space Environments Conference, June 27 - 30, 2011, Honolulu, Hawaii.

7 Collier, F. S., Thomas, R, Nickol, C. A., Lee, Chi-Ming, Tong, M. "Environmentally Responsible Aviation - Real Solutions for Environmental Challenges Facing Aviation, $27^{\text {th }}$ International Congress of the Aeronautical Sciences, Paper No. 802, Nice, France, 19-24 September, 2010.

$8 \quad$ McCullers, L. A., "FLOPS Flight Optimization System, FLOPS manual.doc,” FLOPS User Manual, updated Dec. 2009. 
9 Nickol, C.L. and McCullers, L.A., "Hybrid Wing Body Configuration System Studies," AIAA-2009-0931, 47th AIAA Aerospace Sciences Meeting and Exhibit, January 5-8, 2009, Orlando, Florida.

10 McCullers, L. A.: "FLOPS Weight Module Documentation, Wate.doc," FLOPS Users Manual, April 2008.

11 Bradley, K.R., “A Sizing Methodology for the Conceptual Design of Blended-Wing-Body Transports," NASA/CR-2004213016, NASA Langley Research Center, Hampton, Virginia, September 2004.

12 Hahn, A., "Vehicle Sketch Pad: A Parametric Geometry Modeler for Conceptual Aircraft Design," 48th AIAA Aerospace Sciences Meeting and Exhibit, January 4-7, 2010, Orlando, Florida.

13 Li, V. and Velicki, A., "Advanced PRSEUS Structural Concept Design and Optimization," AIAA-2008-5840, 12th AIAA/ISSMO Multidisciplinary Analysis and Optimization Conference, 10-12 September 2008, Victoria, British Columbia, Canada.

14 Velicki, A., Thrash, P., and Jegley, D., “Airframe Development for the Hybrid Wing Body Aircraft,” AIAA-2009-932, 47th AIAA Aerospace Sciences Meeting Including The New Horizons Forum and Aerospace Exposition, January 5-8, 2009, Orlando, Florida.

15 Yovanof, N.P., Velicki, A., and Li, V., "Advanced Structural Stability Analysis of a Noncircular, BWB-Shaped Vehicle," AIAA-2009-2452, 50th AIAA/ASME/ASCE/AHS/ASC Structures, Structural Dynamics, and Materials Conference, May 4-7, 2009, Palm Springs, California.

16 MSC Nastran 2008, Quick Reference Guide, MSC Software Corporation, 2 MacArthur Place, Santa Ana, CA 92707, USA, 2008, p. 2077.

17 MSC Nastran 2005 r3, Design Sensitivity and Optimization, User's Guide, MSC Software Corporation, 2 MacArthur Place, Santa Ana, CA 92707, USA, 2005.

18 Velicki, A., Damage Arresting Composites for Shaped Vehicles, NASA/CR-2009-215932, The Boeing Company, Huntington Beach, California, NASA Langley Research Center, Hampton, Virginia, 23681-2199, September 2009.

19 Nickol, C.L., "Hybrid Wing Body Configuration Scaling Study," AIAA-2012-0337, 50 ${ }^{\text {th }}$ AIAA Aerospace Sciences Meeting and Exhibit, January 9-12, 2012, Nashville, Tennessee. 